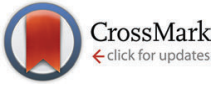

Cite this: J. Mater. Chem. C, 2016, 4, 10265

Received 30th June 2016,

Accepted 4th October 2016

DOI: $10.1039 / c 6 t c 02717 b$

www.rsc.org/MaterialsC

\title{
Spectroscopic characterization of charge carriers of the organic semiconductor quinacridone compared with pentacene during redox reactions $\dagger$
}

\author{
Sandra Enengl, ${ }^{\mathrm{ab}}$ Christina Enengl, ${ }^{\mathrm{ab}}$ Sandra Pluczyk, ${ }^{\mathrm{c}}$ Eric D. Glowacki, ${ }^{\mathrm{b}}$ \\ Mieczyslaw Lapkowski, ${ }^{c d}$ Eitan Ehrenfreund, ${ }^{e}$ Helmut Neugebauer ${ }^{\mathrm{b}}$ and \\ Niyazi Serdar Sariciftci ${ }^{b}$
}

\begin{abstract}
In recent research, the pigment quinacridone, a hydrogen-bonded organic semiconductor, has gained attention in electronic device and catalysis applications due to its extraordinary stability. In this work, we combine electrochemistry with spectroscopy ranging from UV-VIS to mid-IR, allowing a deeper understanding and also structural analysis of the redox products. This is important for materials used in bioelectronic applications, such as quinacridone which is a promising candidate. Several absorption bands related to sub-gap transitions appear upon redox reactions in this spectral range. Optical experiments are correlated with electron paramagnetic resonance measurements, proving the formation of different kinds of charge carriers. The results are discussed and compared with those for the all-carbon five-ring analogous molecule pentacene, because both pigments are candidates for ambipolar organic field-effect transistors, showing similar charge carrier mobilities. In the case of quinacridone, the charged species created upon redox reactions are more localized on different functional groups in the heteroatomic structure than in pentacene.
\end{abstract}

\section{Introduction}

Hydrogen-bonded pigments such as quinacridone have recently gained attention as organic semiconductors, combining stability (even under ambient conditions) and low-cost with relatively high ambipolar charge carrier mobility. ${ }^{1-6}$ This class of pigments consists of dye molecules, crystallizing according to the interplay of intermolecular hydrogen-bonding and $\pi-\pi$ interactions to form a crystal-lattice structure. Their optical properties are drastically different than from the monomeric dye constituents. ${ }^{7,8}$ Such materials are characterized by excellent stability as colorants, and as such have found widespread application in robust outdoor paints and printing inks which are notable for being nontoxic and environmentally benign.,

\footnotetext{
${ }^{a}$ Institute of Polymer Science, Johannes Kepler University Linz, Altenbergerstraße 69, 4040 Linz, Austria.E-mail: Sandra.Enengl@jku.at

${ }^{b}$ Linz Institute for Organic Solar Cells (LIOS), Physical Chemistry, Johannes Kepler University Linz, Altenbergerstraße 69, 4040 Linz, Austria ${ }^{c}$ Department of Physical Chemistry and Technology of Polymers, Faculty of Chemistry, Silesian University of Technology, 9 Marcina Strzody street, 44-100 Gliwice, Poland

${ }^{d}$ Center of Polymer and Carbon Materials, Polish Academy of Sciences, 34 M. Curie-Sklodowskiej street, 41-819 Zabrze, Poland

${ }^{e}$ Department of Physics and Solid State Institute, Technion-Israel Institute of Technology, Technion City, 32000 Haifa, Israel

$\dagger$ Electronic supplementary information (ESI) available. See DOI: 10.1039/c6tc02717b
}

Recently, this class of materials has received attention as alternative low-cost semiconductors, with operational stability in aqueous environments suggesting applications in bioelectronics ${ }^{1,10,11}$ and photocatalysis. ${ }^{12}$ In these works, specific analysis experiments are performed verifying the handling of such hydrogen-bonded organic semiconductors in aqueous environments. Therefore, the fundamental electrochemical behavior and structure of redox products of hydrogen-bonded pigments are of interest. Herein, we characterize spectroscopically the hydrogen-bonded organic semiconductor quinacridone which is known to undergo electrochemical reduction and oxidation reactions. $^{2}$

Electrochemistry is a widespread technique for studying the kinetics and the mechanisms of intermediates and products of electrochemical reactions. An overview of general methods can be found in ref. 13. Radical ions are often products of electrochemical methods in organic compounds. For electrochemical investigations, cyclic voltammetry is most widely used. This method provides important information of charge transfer in a system, but the extent of the detail varies with the complexity of the system. In this approach, it is complicated to obtain information of the structure of the reduced and oxidized species at the molecular level. To gain insights into the molecular structures of intermediates and products in electrochemical reactions, a combination of electrochemistry with spectroscopic methods, 
known as spectroelectrochemistry, is required. ${ }^{14,15}$ Spectroelectrochemistry has been employed for several decades to study the redox behavior of inorganic, organic, and biological molecules. ${ }^{16,17}$ In particular, in the UV-VIS to IR range the spectrum of the intermediate shows vibrational components as well as electronic transitions. $^{14}$ These measurements belong to one of the best methods to explore the redox behavior of materials.

Device characterizations as well as spectroscopic measurements have already been performed on quinacridone compared to pentacene. The characterization of organic field-effect transistors (OFETs) has shown that the mobility of quinacridone is comparable to the mobility of pentacene in similarly prepared devices. ${ }^{3}$ However, differences in the charge carrier concentration were found. ${ }^{18}$ Further, these compounds have been oxidized by using iodine as an oxidation agent and spectroscopic changes have been elucidated in the UV-VIS up to mid-IR range, including electron paramagnetic resonance (EPR) and conductivity measurements. ${ }^{18}$ While pentacene shows the formation of radical cations, which are transformed to a spinless species in a higher oxidation state, quinacridone shows only the formation of radical cations. In addition, this spectroscopic study has been connected to device performance to explain the enhanced chemical stability of the semiconductor quinacridone, which for example has not been achieved for pentacene. Direct comparisons between pentacene and quinacridone in terms of OFET stability have been carried out, where the rapid decline in the performance of pentacene in comparison with quinacridone is apparent. ${ }^{2}$ Density functional theory (DFT) calculations addressing the enhanced chemical stability issue for quinacridone have also been reported in the literature. ${ }^{18}$ Herein, we discuss a technique which is an extension of the mentioned results, where spectroscopic changes of both compounds are considered by using electrochemical methods. The main advantages of spectroelectrochemistry are that reduction reactions can be performed more easily, the redox levels can be controlled by applying a certain potential as well as higher oxidized species can be analyzed, which may be difficult to achieve upon chemical oxidation reactions.

In this work, we have evaluated the molecular-scale changes that occur during redox reactions in the quinacridone heteroatomic structure by using spectroelectrochemical techniques in the UV-VIS and infrared range. Pentacene, an all-carbon fivering analog of quinacridone, is characterized in comparison. We have employed the in situ attenuated total reflection (ATR) IR spectroelectrochemistry technique. Herein, the term in situ means detecting spectroscopic changes during electrochemical reactions, e.g. oxidation and reduction. This method allows the tracking of electronic as well as vibrational changes occurring during redox reactions. In addition, in the case of quinacridone the localization of charged species on different functional groups in the heteroatomic ring system can be seen. Evolution of new electronic sub-gap states is apparent when applying transmissionmode in situ spectroelectrochemistry in the UV-VIS range. Finally, the electrochemical formation of radical species is reported using in situ EPR spectroscopy. These three in situ methods allow a picture of the molecular structures of the redox species of quinacridone to be obtained, which shows differences when compared with the all-carbon analogous molecule pentacene.

\section{Experimental techniques}

\subsection{Material processing}

Quinacridone (TCI) was purified by repeated temperature gradient sublimation and pentacene (Aldrich) was processed similarly. We deposited the studied pigments by vacuumevaporation either on glass/ITO (15 $\Omega \mathrm{sq}^{-1}$, Xinyan) which was pre-cleaned by an ultrasonic bath in acetone, isopropyl alcohol, and deionized water and then dried under nitrogen, or on a $\mathrm{ZnSe} / \mathrm{Pt}$ crystal. The thickness for quinacridone samples was about 80-100 $\mathrm{nm}$ and for pentacene ones 60-80 nm, which was measured by using a Dektak profilometer (Bruker). Next, a thin layer of poly(vinyl alcohol) (PVA, 99+\% hydrolyzed, Aldrich) solution was spin-coated onto the thin-film of the compounds ${ }^{19}$ which protects molecules from dissolving during electrochemical studies.

\subsection{Electrochemistry}

All electrochemical experiments were carried out under nitrogen atmosphere in a glovebox and performed using a JAISSLE potentiostat-galvanostat IMP 88 PC. Cyclic voltammetry was applied to determine the oxidation and reduction potentials of these pigments, i.e. quinacridone and pentacene. The considered material was deposited on glass/ITO as described above which was used as a working electrode (WE). A Ag/AgCl wire was used as a quasi-reference electrode (QRE), see ref. 20 for fabrication, and $\mathrm{Pt}$ was used as a counter electrode (CE) in $0.1 \mathrm{M}$ tetrabutylammonium hexafluorophosphate $\left(\mathrm{TBAPF}_{6}\right.$, $\geq 99 \%$, Fluka Analytical) in acetonitrile (Roth) as an anhydrous electrolyte solution. The QRE was calibrated using a ferrocene/ ferrocenium redox couple $\left(\mathrm{Fc} / \mathrm{Fc}^{+}\right)$. The half-wave potential for $\mathrm{Fc} / \mathrm{Fc}^{+}$was found to be $+371 \mathrm{mV}$ vs. QRE. In both cases, scan rates of $10 \mathrm{mV} \mathrm{s}^{-1}$ were performed.

\subsection{Spectroelectrochemistry}

2.3.1 UV-VIS and mid-IR measurements. Spectroelectrochemical measurements were carried out in the mid-IR range as well as in the UV-VIS range. The spectroelectrochemical measurements in the visible range were performed in transmittance mode. The experiments were carried out inside a glovebox using an AvaSpec-2048-USB2 fiber-optic spectrometer (Avantes). In this setup, the glass/ITO/studied material/PVA substrate served as a WE, Pt as a $\mathrm{CE}$, and a $\mathrm{Ag} / \mathrm{AgCl}$ wire as a QRE. The same electrolyte solution as mentioned above was used. A schematic drawing of this spectroelectrochemical cell is depicted in Fig. 2(d).

The infrared measurements were performed on an IFS 66/S spectrometer (Bruker) using the Fourier transform infrared (FTIR) technique. The experiments have been carried out working in the ATR mode. ${ }^{21-23}$ A ZnSe crystal (Harrick) was sputtered with a thin layer of Pt where afterwards a thin-film of the pigment was evaporated. The $\mathrm{ZnSe} / \mathrm{Pt} / \mathrm{studied}$ material/PVA reflection element served as the WE. In the flow cell, a Pt electrode was used as the 
$\mathrm{CE}$ and a $\mathrm{Ag} / \mathrm{AgCl}$ wire was used as the QRE. During the experiments, the same non-aqueous electrolyte solution as mentioned above was used for in situ spectroelectrochemical measurements. The setup for the spectroelectrochemical flow cell is shown schematically in Fig. 6(f).

Spectral changes in the UV-VIS as well as in the mid-IR range during the electrochemical oxidation and reduction reactions of quinacridone and pentacene were measured with potential steps of $100 \mathrm{mV}$, respectively. In the mid-IR range, the difference spectra are shown for quinacridone and pentacene, where the spectrum at $0 \mathrm{mV}$ is denoted as the reference spectrum $T_{\text {ref. }}$ All other related spectra during oxidation or reduction correspond to $T_{\text {redox }}$, where $-\log \left(T_{\text {redox }} / T_{\text {ref }}\right)$ was calculated.

2.3.2 Electron paramagnetic resonance (EPR) measurements. Thin-films of quinacridone or pentacene were evaporated on glass/ ITO (20 $\Omega \mathrm{sq}^{-1}$, präzisions glas \& optik) as mentioned before, respectively. Further, a PVA layer was spin-coated as described above for in situ EPR measurements. The experiments were performed on a JEOL JES-FA 200, X-band CW-EPR spectrometer operating at $100 \mathrm{kHz}$ field modulation. This spectrometer was coupled with an Eco Chemie AUTOLAB potentiostat-galvanostat model PGSTAT100N in order to conduct electrochemical investigations. A flat spectroelectrochemical cell equipped with a glass/ ITO/studied material/PVA as the WE, a platinum spiral as the CE, and a silver wire as the QRE was used. This QRE was calibrated with $\mathrm{Fc} / \mathrm{Fc}^{+}$. Again, we used a $0.1 \mathrm{M} \mathrm{TBAPF}_{6}$ (Sigma Aldrich 98\%) in acetonitrile (Acros Organics 99.9\% extra dry over Molecular Sieves, AcroSeal) solution as an electrolyte solution. In Fig. 4(e), the experimental setup for this EPR cell is shown. We applied potentials around $0 \mathrm{mV}, 950 \mathrm{mV}$, and $1300 \mathrm{mV}$ for pentacene, and for quinacridone we measured around $0 \mathrm{mV}, 1200 \mathrm{mV}$, and $1650 \mathrm{mV} v$ s. Ag/AgCl QRE. Only the oxidation part was performed for both pigments, because it is hard to achieve very low potentials for reducing investigated compounds for this setup configuration. For this type of electrochemical cell, the possibilities to purge this cell with inert gas are limited which would be necessary for reduction reactions.

\section{Results and discussion}

\subsection{Cyclic voltammetry}

Cyclic voltammetry is used for basic characterization of the electrochemical oxidation and reduction of materials. In Fig. 1, we show cyclic voltammograms for (a) pentacene and (c) quinacridone. As an inset, the schematic chemical structure of these considered molecules is appended. Both pigments can be oxidized and reduced and a characteristic feature of these pigments is the different number of redox peaks.

For pentacene, Fig. 1(a), we observe one well-defined oxidation peak, which starts at $650 \mathrm{mV}$ and reaches its maximum at $1280 \mathrm{mV}$. The reduction starts at $-1140 \mathrm{mV}$, depicted in Fig. 1(b), and shows a peak at $-1630 \mathrm{mV}$. The electrochemically determined HOMO-LUMO gap is $1.8 \mathrm{eV}$ which is calculated from the difference in the onset of the reduction and onset of the oxidation from cyclic voltammogram data.
Quinacridone shows two well-defined oxidation peaks. The first oxidation step of quinacridone, see Fig. 1(c), starts at a potential of $780 \mathrm{mV}$ and has its maximum at $1270 \mathrm{mV}$. Then, the second oxidation step starts and reaches its maximum at $1670 \mathrm{mV}$. In the case of reduction, the reaction starts at a potential of $-1190 \mathrm{mV}$. In Fig. 1(d), the onset of the first reduction step in the cyclic voltammogram is shown separately. Further, the cyclic voltammogram shows two reduction peaks, one at $-1970 \mathrm{mV}$ which is pronounced and the other one appears as a small shoulder at $-1620 \mathrm{mV}$, indicating the first reduction peak, as will be discussed later in the Spectroscopic results section. This information is required for further spectroscopic investigations. Thus, the electrochemically determined HOMO-LUMO gap is $2 \mathrm{eV}$. The analysis of the UV-VIS and infrared spectra as well as EPR measurements performed by changing the potential allows a better understanding of the nature of the redox process.

\subsection{Oxidation}

3.2.1 UV-VIS measurements. Fig. 2(a) shows the changes in absorption for pentacene by changing the potential between $0 \mathrm{mV}$ and $1300 \mathrm{mV}$. The black curve, corresponding to an applied potential of $0 \mathrm{mV}$, shows the absorption spectrum of a pristine pentacene thin-film. There are four peaks visible in this spectrum. Absorption bands at $630 \mathrm{~nm}(1.97 \mathrm{eV})$ and $670 \mathrm{~nm}(1.85 \mathrm{eV})$ are ascribed to the Davydov doublet of the $0-0$ transition, and the other two peaks at $545 \mathrm{~nm}(2.28 \mathrm{eV})$ and $580 \mathrm{~nm}(2.14 \mathrm{eV})$ to the doublet of the $0-1$ band as described in ref. 24 and 25. These four bands at $630 \mathrm{~nm}(1.97 \mathrm{eV}), 670 \mathrm{~nm}$ $(1.85 \mathrm{eV}), 545 \mathrm{~nm}(2.28 \mathrm{eV})$, and $580 \mathrm{~nm}(2.14 \mathrm{eV})$ decrease by applying higher potentials. From now on, we define these four peaks as the main absorption band pattern. New peaks arise at $420 \mathrm{~nm}(2.95 \mathrm{eV})$ and $835 \mathrm{~nm}(1.49 \mathrm{eV})$. It is noteworthy that the absorption band at $420 \mathrm{~nm}(2.95 \mathrm{eV})$ appears after applying a potential of $700 \mathrm{mV}$ and gets more and more pronounced as oxidation proceeds, while the band at $835 \mathrm{~nm}(1.49 \mathrm{eV})$ significantly appears only after applying a potential higher than $1100 \mathrm{mV}$. This behavior will be discussed together with infrared data. In addition, two isosbestic points appear. One can be seen at $500 \mathrm{~nm}(2.48 \mathrm{eV})$, indicating the transformation of the pristine material into an oxidized species. The second isosbestic point at $700 \mathrm{~nm}(1.77 \mathrm{eV})$ appears later after the absorption band at $835 \mathrm{~nm}(1.49 \mathrm{eV})$ is pronounced. This might be an indication that the oxidized species is transformed into another species, as will be discussed later.

The in situ spectroelectrochemical oxidation for quinacridone in the same spectral range is measured by changing the potential between $0 \mathrm{mV}$ and $1700 \mathrm{mV}$. Fig. 2(b) shows the spectral changes during the first oxidation step of quinacridone by changing the potential between $0 \mathrm{mV}$ and $1300 \mathrm{mV}$. The black curve at $0 \mathrm{mV}$ shows the absorption spectrum of a pristine quinacridone thin-film. The three peaks at $490 \mathrm{~nm}(2.53 \mathrm{eV}), 525 \mathrm{~nm}(2.36 \mathrm{eV})$, and $560 \mathrm{~nm}(2.21 \mathrm{eV})$ can be assigned to the vibronic structures with $0-0,0-1$, and $0-2$ transitions, respectively, similarly as described in ref. 26. Again, these three peaks will be defined as the main absorption band pattern throughout. The main 

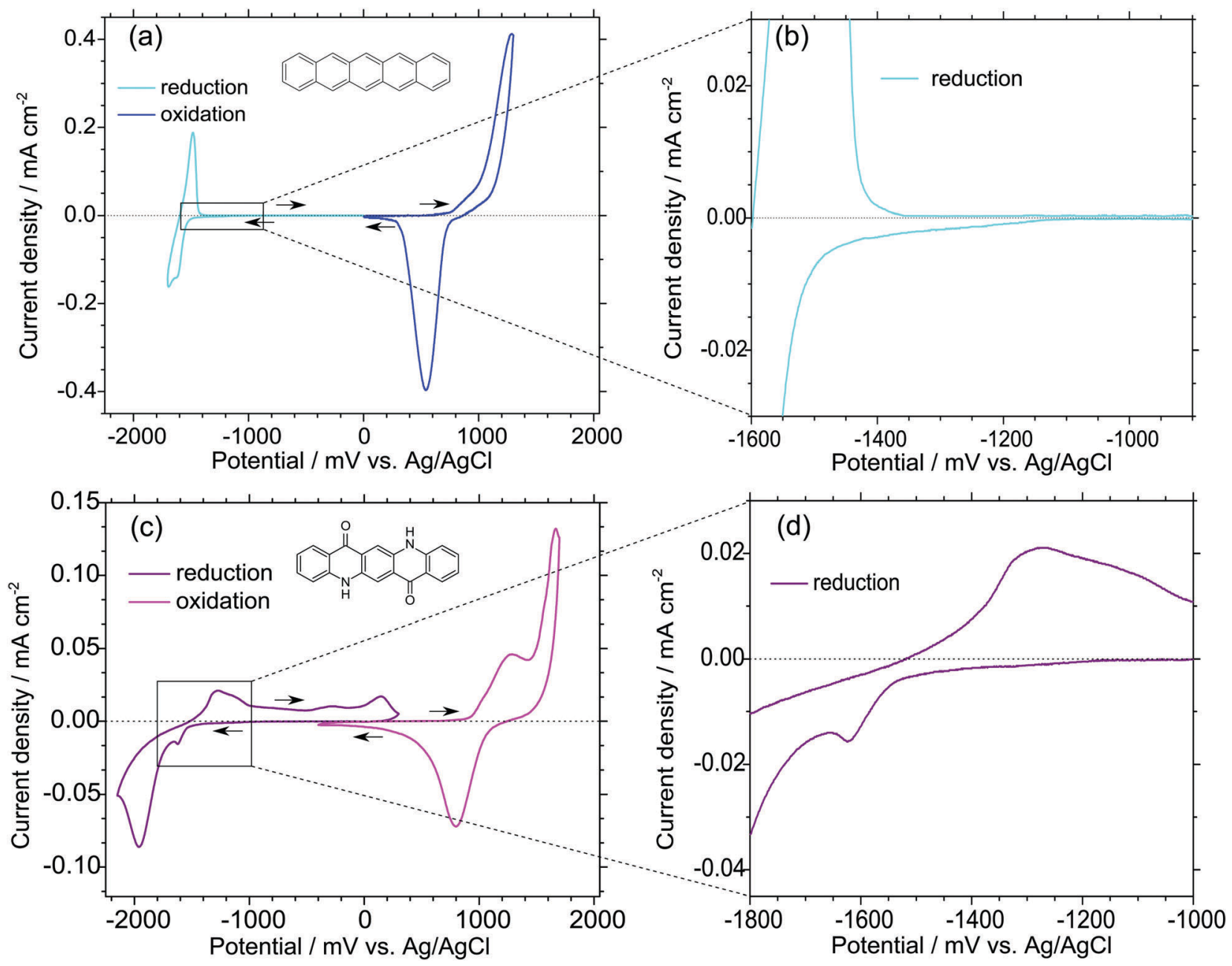

Fig. 1 The oxidation and reduction reactions of (a) pentacene and (c) quinacridone are shown. The onset of reduction of pentacene is depicted separately in (b) and of the first reduction step of quinacridone in (d). The insets in (a) and (b) show the schematic chemical structure of pigments pentacene and quinacridone, respectively.

absorption band pattern decreases by applying higher potentials and small changes in absorption appear for the region around $625 \mathrm{~nm}(1.98 \mathrm{eV})$. A similar behavior in absorption during oxidation of the quinacridone thin-film has already been observed and discussed ${ }^{18}$ where chemical oxidation with iodine vapor has been performed. From these results, we conclude that potentials up to $1300 \mathrm{mV}$ can be reached by oxidizing quinacridone with iodine vapor. During the second oxidation step, see Fig. 2(c), the potential is changed between $1400 \mathrm{mV}$ and $1700 \mathrm{mV}$. The peak at $625 \mathrm{~nm}(1.98 \mathrm{eV})$ increases significantly, getting more and more pronounced as oxidation proceeds. Further, two new absorption bands related to electronic transitions around $380 \mathrm{~nm}(3.26 \mathrm{eV})$ and $870 \mathrm{~nm}(1.43 \mathrm{eV})$ appear, increasing by applying higher potentials. In addition, during the second oxidation step of this pigment, the main absorption band pattern gradually decreases. This figure shows also two isosbestic points at $580 \mathrm{~nm}(2.14 \mathrm{eV})$ and $515 \mathrm{~nm}(2.41 \mathrm{eV})$, indicating a transformation of the species obtained during the first oxidation step into another one upon the second oxidation step.
3.2.2 IR measurements. A detailed study is also performed in the infrared range to allow structural analysis of different oxidized species due to vibrational changes. In Fig. 3(a), we see the difference spectra during oxidation of pentacene in the mid-IR range by changing the potential in the same range as has already been mentioned in UV-VIS measurements. The reference spectrum corresponds to the spectrum at $0 \mathrm{mV}$. As oxidation starts, around $700 \mathrm{mV}$, a broad absorption band appears, increasing by applying higher potentials. The maximum of this absorption band is around $6130 \mathrm{~cm}^{-1}(0.76 \mathrm{eV})$ by applying potentials up to $1000 \mathrm{mV}$. As oxidation proceeds, it undergoes a redshift, reaching finally a value of $5790 \mathrm{~cm}^{-1}$ $(0.72 \mathrm{eV})$. The strong negative peaks, appearing in the range between $3600 \mathrm{~cm}^{-1}(0.45 \mathrm{eV})$ and $2700 \mathrm{~cm}^{-1}(0.33 \mathrm{eV})$ will be discussed together with Fig. 3(b). The oxidation reaction of pentacene describes an irreversible process as can be seen in ESI, $\dagger$ Fig. S1, because the spectra do not show the spectral behavior of the pristine material. The spectral changes in the range between $1700 \mathrm{~cm}^{-1}(0.21 \mathrm{eV})$ and $650 \mathrm{~cm}^{-1}(0.08 \mathrm{eV})$ are plotted in Fig. 3(b). The graph shows again the difference 


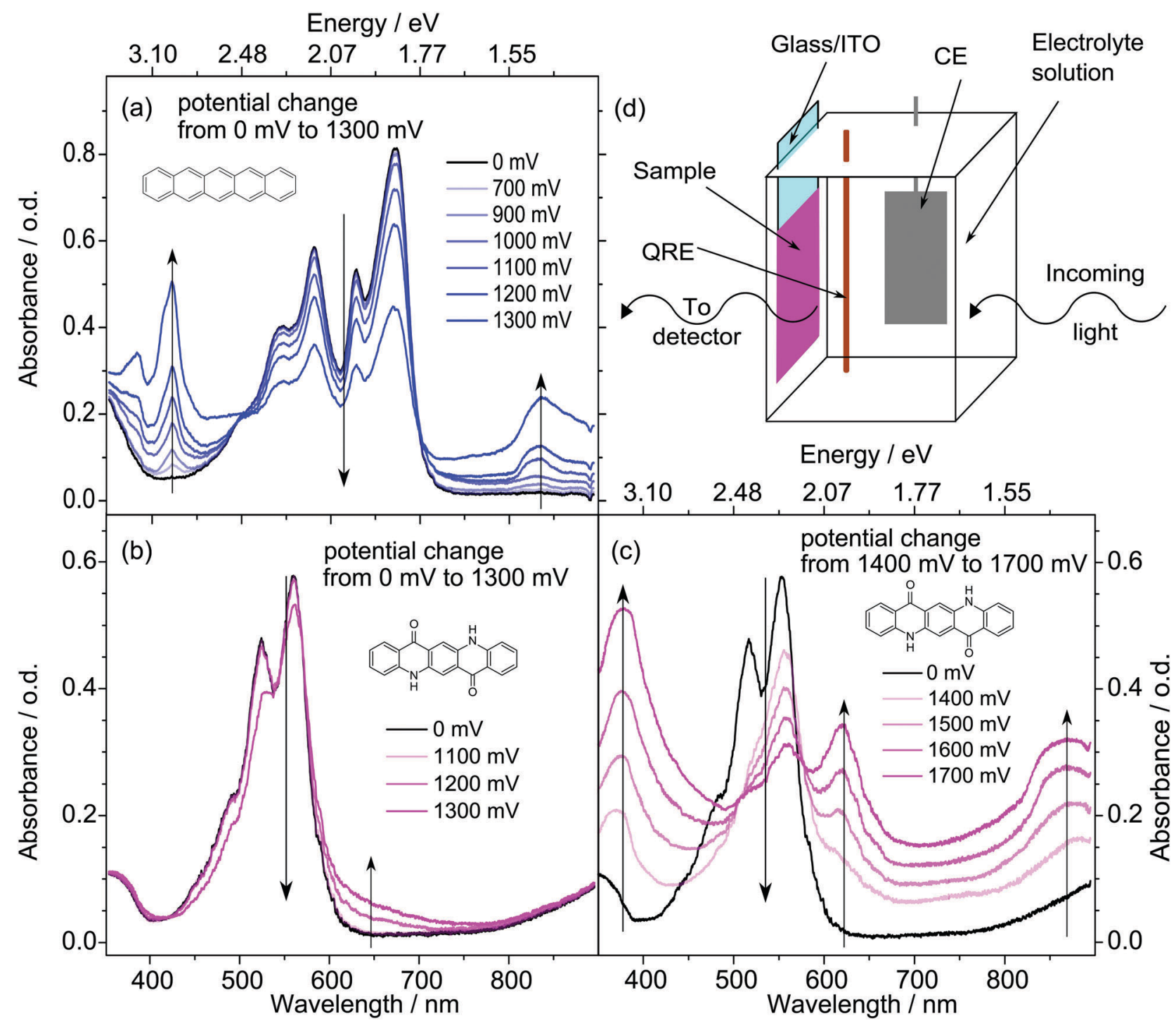

Fig. 2 Spectral changes in the UV-VIS range during electrochemical oxidation of (a) pentacene by changing the potential between $0 \mathrm{mV}$ and $1300 \mathrm{mV}$ and (b) quinacridone during the first oxidation step by changing the potential between $0 \mathrm{mV}$ and $1300 \mathrm{mV}$. (c) The second oxidation step of quinacridone by changing the potential between $1400 \mathrm{mV}$ and $1700 \mathrm{mV}$. In all measurements, the spectrum obtained at $0 \mathrm{mV}$ shows the absorption spectrum of the considered pristine material. The direction of spectral changes is indicated with arrows in these figures. (d) The experimental setup for in situ UV-VIS spectroelectrochemistry.

spectra with the spectrum at $0 \mathrm{mV}$ taken as the reference spectrum. At low oxidation potentials (up to $1000 \mathrm{mV}$ ) hardly any changes are visible. Just the baseline of these spectra shifts upwards. Only one positive peak at $840 \mathrm{~cm}^{-1}$ is pronounced which is attributed to the $\mathrm{PF}_{6}{ }^{-}$vibration. This is the counterion of the electrolyte salt which balances the positive charge formed on the molecule during oxidation. After applying a potential of $1100 \mathrm{mV}$ (small changes already recognizable at $1000 \mathrm{mV}$ ) vibrations change significantly. New positive peaks arise while others disappear, getting more pronounced as oxidation proceeds. The positive peaks in the range between $1140 \mathrm{~cm}^{-1}$ and $1560 \mathrm{~cm}^{-1}$ represent the changes in the $-\mathrm{C}=\mathrm{C}-$ and $-\mathrm{C}-\mathrm{H}$ vibrations. Clearly, the peak at $840 \mathrm{~cm}^{-1}$ increases further upon oxidation. The negative peaks arising in Fig. 3(a) in the broad absorption band as well as in Fig. $3(\mathrm{~b})$ in the range between $1700 \mathrm{~cm}^{-1}(0.21 \mathrm{eV})$ and $650 \mathrm{~cm}^{-1}(0.08 \mathrm{eV})$ correspond to the vibrations of the pristine pentacene film covered with PVA, acting as a protection layer. These vibrations of pristine pentacene are reduced in intensity more and more by applying higher oxidation potentials. This effect can be related to the changes in the molecular structure. Due to the complex geometry for in situ ATR-FTIR measurements as well as the multilayered structure of the considered samples, spectral incompensations are shown to be much stronger, resulting in an interplay between the vibrations of the pristine pentacene and its protection layer PVA.

We summarize the essential features obtained by in situ spectroelectrochemical studies of pentacene in the UV-VIS and mid-IR range. Although there is only one well-defined oxidation peak in the cyclic voltammogram, see Fig. 1(a), we distinguish 


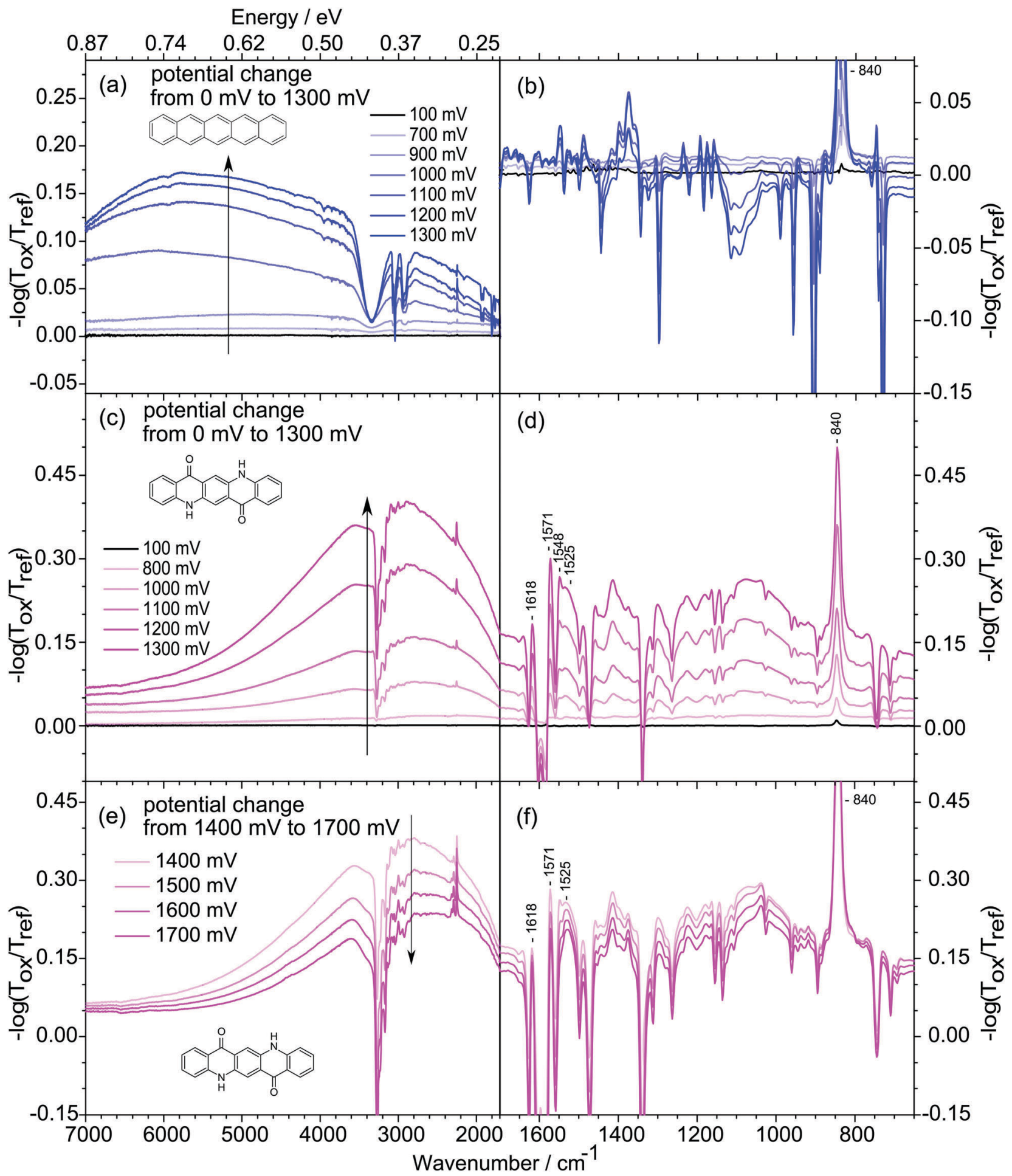

Fig. 3 (a) Spectral changes in the mid-IR range during electrochemical oxidation of pentacene by applying a potential between $0 \mathrm{mV}$ and $1300 \mathrm{mV}$ with the spectrum at $0 \mathrm{mV}$ taken as the reference spectrum. (b) The corresponding spectral range between $1700 \mathrm{~cm}^{-1}(0.21 \mathrm{eV}) \mathrm{and} 650 \mathrm{~cm}{ }^{-1}(0.08 \mathrm{eV})$. (c) The first oxidation step of quinacridone by changing the potential between $0 \mathrm{mV}$ and $1300 \mathrm{mV}$ and (e) the second oxidation step by changing the potential between $1400 \mathrm{mV}$ and $1700 \mathrm{mV}$. The reference spectrum is again taken at $0 \mathrm{mV}$. (d) and (f) The corresponding spectral ranges between $1700 \mathrm{~cm}^{-1}(0.21 \mathrm{eV})$ and $650 \mathrm{~cm}^{-1}(0.08 \mathrm{eV})$, respectively. The arrows in the graphs indicate the direction of spectral changes.

between low and high oxidation due to the in situ spectroscopic results. By applying potentials up to $1000 \mathrm{mV}$, at a low oxidation level, the main absorption band pattern decreases and at the same time a new band in the UV-VIS range at $420 \mathrm{~nm}(2.95 \mathrm{eV})$ appears. Simultaneously, a broad absorption band with its maximum at $6130 \mathrm{~cm}^{-1}(0.76 \mathrm{eV})$ arises in the mid-IR range. 
It is remarkable that there are hardly any significant changes in vibrations in the range between $1700 \mathrm{~cm}^{-1}(0.21 \mathrm{eV})$ and $650 \mathrm{~cm}^{-1}(0.08 \mathrm{eV})$. At a higher oxidation level, after reaching a potential of $1100 \mathrm{mV}$ (moderate changes in the mid-IR range between $1700 \mathrm{~cm}^{-1}(0.21 \mathrm{eV})$ and $650 \mathrm{~cm}^{-1}(0.08 \mathrm{eV})$ are already observed at $1000 \mathrm{mV}$ ) a further peak in the UV-VIS range at $835 \mathrm{~nm}(1.49 \mathrm{eV})$ gets recognizable, while the other peak at $420 \mathrm{~nm}(2.95 \mathrm{eV})$ further increases and the main absorption band pattern still decreases. In addition, the maximum of the absorption band in the mid-IR range shifts to a lower energy, reaching its new maximum at $5790 \mathrm{~cm}^{-1}(0.72 \mathrm{eV})$. In the range between $1700 \mathrm{~cm}^{-1}(0.21 \mathrm{eV})$ and $650 \mathrm{~cm}^{-1}(0.08 \mathrm{eV})$, positive as well as negative peaks appear, indicating changes in the $-\mathrm{C}=\mathrm{C}-$ and $-\mathrm{C}-\mathrm{H}$ vibrations. Similar spectroscopic results have been observed by chemical oxidation of pentacene using iodine as an oxidation agent. ${ }^{18}$

Next, we consider spectroelectrochemistry of quinacridone in the mid-IR range. Its cyclic voltammogram shows two welldefined oxidation peaks in Fig. 1(c), therefore, we consider each oxidation step separately. The spectral changes ascribed to the first oxidation step are shown in Fig. 3(c) and (d) and the optical measurements for the second one are depicted in Fig. 3(e) and (f). Fig. 3(c) shows the difference spectra during the first oxidation step of quinacridone by changing the potential between $0 \mathrm{mV}$ and $1300 \mathrm{mV}$ with the spectrum at $0 \mathrm{mV}$ taken as the reference spectrum. As oxidation starts around $800 \mathrm{mV}$, a broad absorption band develops up to a potential of $1300 \mathrm{mV}$ which increases due to higher potentials. The maximum of this broad absorption band is around $2890 \mathrm{~cm}^{-1}(0.36 \mathrm{eV})$. The corresponding spectral changes in the range between $1700 \mathrm{~cm}^{-1}(0.21 \mathrm{eV})$ and $650 \mathrm{~cm}^{-1}$ $(0.08 \mathrm{eV})$ are shown in Fig. 3(d). The huge positive peak at $840 \mathrm{~cm}^{-1}$ is again the characteristic peak for the $\mathrm{PF}_{6}{ }^{-}$vibration. The peaks located at $1618 \mathrm{~cm}^{-1}$ and $1525 \mathrm{~cm}^{-1}$ correspond to the $-\mathrm{C}=\mathrm{N}$ - stretching vibration, while those at $1571 \mathrm{~cm}^{-1}$ and $1548 \mathrm{~cm}^{-1}$ are assigned to the $-\mathrm{C}=\mathrm{C}-$ vibration. The peaks at $1603 \mathrm{~cm}^{-1}$ and $1582 \mathrm{~cm}^{-1}$, indicating the $-\mathrm{N}-\mathrm{H}$ vibration of the pristine quinacridone thin-film disappear upon oxidation. The other positive and negative peaks represent $-\mathrm{C}-\mathrm{H}$ and $-\mathrm{C}=\mathrm{C}-$ deformation vibrations.

Spectral changes during the second oxidation step are shown in Fig. 3(e). For this measurement, we change the potential between $1400 \mathrm{mV}$ and $1700 \mathrm{mV}$ and the reference spectrum corresponds to the spectrum at $0 \mathrm{mV}$. Upon this potential change, the broad absorption band which appears during the first oxidation step decreases in absorption in the infrared regime. The first and the second oxidation reactions demonstrate the reversibility of quinacridone as is shown in ESI, $\dagger$ Fig. S2. The corresponding spectral changes in the range between $1700 \mathrm{~cm}^{-1}(0.21 \mathrm{eV})$ and $650 \mathrm{~cm}^{-1}(0.08 \mathrm{eV})$ are shown in Fig. 3(f) for the second oxidation step. Again, the pronounced positive peak located at $840 \mathrm{~cm}^{-1}$ represents the $\mathrm{PF}_{6}{ }^{-}$vibration from the electrolyte salt. The signals at $1618 \mathrm{~cm}^{-1}$ and $1525 \mathrm{~cm}^{-1}$ are attributed to the $-\mathrm{C}=\mathrm{N}$ - stretching vibration and increase further upon oxidation. The $-\mathrm{N}-\mathrm{H}$ vibrations of the pristine quinacridone thin-film located at $1603 \mathrm{~cm}^{-1}$ and $1582 \mathrm{~cm}^{-1}$ decrease further. All other positive peaks are assigned to $-\mathrm{C}-\mathrm{H}$ and $-\mathrm{C}=\mathrm{C}$ - deformation vibrations. Interestingly, some of the peaks indicating the $-\mathrm{C}=\mathrm{C}$ - vibration upon the first oxidation step either decrease or continuously increase upon the second oxidation step. Thus, the vibration at $1548 \mathrm{~cm}^{-1}$ disappears and the peak at $1571 \mathrm{~cm}^{-1}$ increases further. The negative peaks arising in Fig. 3(c)-(f) correspond to the vibrations of the pristine quinacridone film. The reason why they appear as negative peaks is the same as has already been mentioned for pentacene.

The spectroscopic results which are obtained for quinacridone during the two oxidation steps are summarized. During the first oxidation step, up to a potential of $1300 \mathrm{mV}$, small changes in absorption around $625 \mathrm{~nm}(1.98 \mathrm{eV})$ are detected in the UV-VIS range, while the main absorption band pattern slightly decreases. Simultaneously, an absorption peak related to electronic transitions appears in the mid-IR range, having its maximum at $2890 \mathrm{~cm}^{-1}(0.36 \mathrm{eV})$. Further, changes in vibrations occur (in the spectral range between $1700 \mathrm{~cm}^{-1}(0.21 \mathrm{eV})$ and $650 \mathrm{~cm}^{-1}$ $(0.08 \mathrm{eV}))$ as it has been described above, see Fig. 3(d), which might be an indication for the formation of a semiquinoid structure as it is known from the formation of a polaron in polyaniline due to the distortion of the geometry of the molecule. ${ }^{27}$ In the case of quinacridone, oxidation does not happen on the conjugated carbon-carbon chain (as it is well known for organic conjugated polymers), but at the free lone pair of the nitrogen atom. Due to symmetry reasons, it does not matter at which of these two nitrogen atoms. Similar results for absorption bands in the UV-VIS and mid-IR range as well as vibrational changes are obtained by chemical oxidation of quinacridone using iodine as an oxidation agent. ${ }^{18}$ Interestingly, only the first oxidation step of quinacridone can be reached by oxidizing quinacridone with iodine. An advantage of electrochemical compared to chemical oxidation is that the oxidation level can be controlled by applying higher potentials, thus the second oxidation step can be reached. Upon the second oxidation step, potentials up to $1700 \mathrm{mV}$ are applied, Fig. 2(c). Several peaks arise at $380 \mathrm{~nm}(3.26 \mathrm{eV}), 625 \mathrm{~nm}$ $(1.98 \mathrm{eV})$, and $870 \mathrm{~nm}(1.43 \mathrm{eV})$ in the UV-VIS range, while the main absorption band pattern significantly decreases. In addition, the broad band in the infrared range, appearing during the first oxidation step, decreases in absorption. Vibrations in the range between $1700 \mathrm{~cm}^{-1}(0.21 \mathrm{eV})$ and $650 \mathrm{~cm}^{-1}$ $(0.08 \mathrm{eV})$ change slightly during the second oxidation compared to the first oxidation. Interestingly, all peaks assigned to $-\mathrm{C}=\mathrm{N}-$ and $-\mathrm{N}-\mathrm{H}$ vibrations increase and decrease in a similar manner as during the first oxidation step, respectively. The vibrations assigned to $-\mathrm{C}=\mathrm{C}$ - aromatic vibrations might be an indication for changing the conjugation through this molecule, which is promoted by aromatic stabilization. Due to the further increase of the $-\mathrm{C}=\mathrm{N}$ - vibrations we suggest that the second oxidation step occurs at the lone pair of the second nitrogen atom.

3.2.3 EPR measurements. The optical properties of the considered molecules are combined with in situ EPR experiments to discuss different kinds of charge carriers formed upon oxidation. In Fig. 4(a), EPR signals registered during oxidation of pentacene are shown by applying potentials around $0 \mathrm{mV}$, 


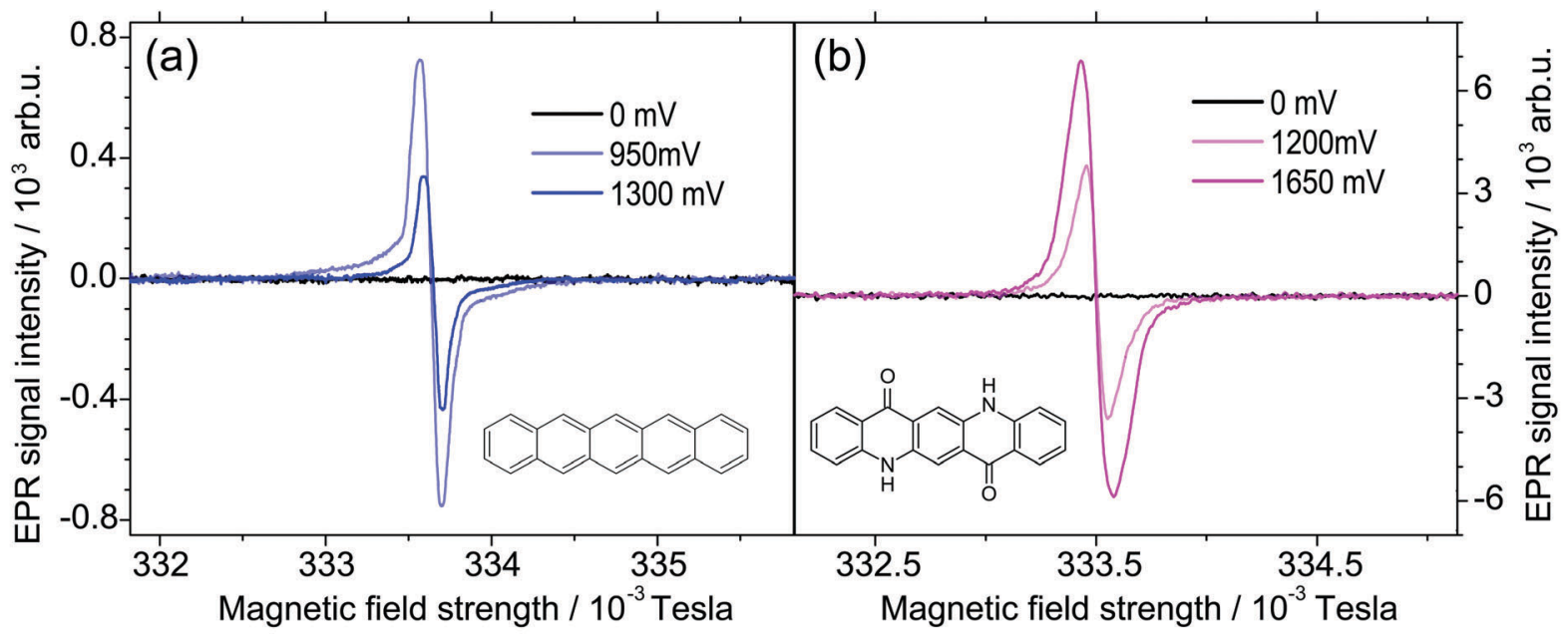

(c)<smiles></smiles>

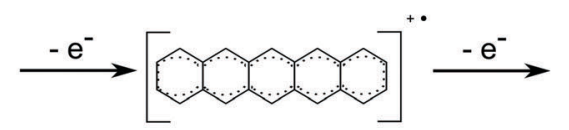

dimerization to (pentacene) $)_{2}^{2+}$

(d)<smiles>CNc1cc2[nH]c3ccccc3c(=O)c2cc1OC</smiles><smiles></smiles>

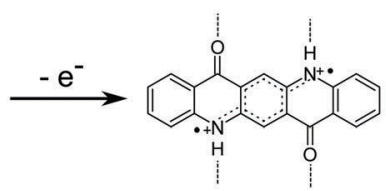

(e)

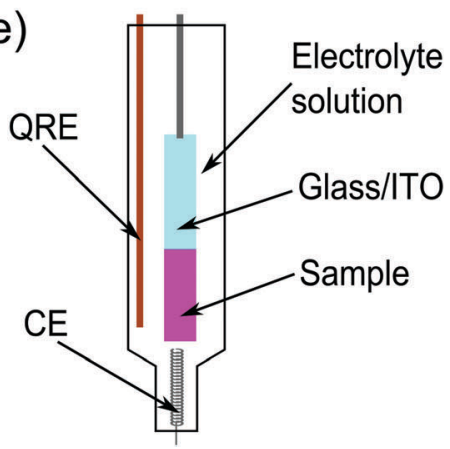

Fig. 4 (a) EPR signals for pentacene by applying potentials around $0 \mathrm{mV}, 950 \mathrm{mV}$, and $1300 \mathrm{mV}$. (b) A persistent increase of the EPR signal for quinacridone is obtained by applying potentials around $0 \mathrm{mV}, 1200 \mathrm{mV}$, and $1650 \mathrm{mV}$. (c) A schematic sketch of the formation of radical cations and subsequently the dimerization of pentacene during oxidation. (d) A schematic sketch of the various oxidation states of quinacridone as deduced from spectroelectrochemistry and EPR measurements. The first oxidation step leads to radical cations, while the second oxidation process gives di(radical cation)s with positive charges localized on the nitrogen atoms. (e) The experimental setup for in situ EPR spectroelectrochemistry.

$950 \mathrm{mV}$, and $1300 \mathrm{mV}$. A different kind of RE was used for EPR measurements than for UV-VIS and mid-IR spectroscopy, therefore, potential values are slightly different. Pentacene does not show any EPR signal in the undoped pristine form which corresponds to a potential of $0 \mathrm{mV}$. The next measurement at $950 \mathrm{mV}$ indicates the formation of unpaired electrons upon oxidation. This potential is a representative of the low oxidation level. At a high oxidation level, demonstrated around $1300 \mathrm{mV}$, the relative number of unpaired spins decreases significantly.

From these facts, we conclude the formation of radical cations in pentacene as oxidation starts. These radical cations show two absorption bands, one in the UV-VIS range and another one in the mid-IR range. Thus, the isosbestic point at $500 \mathrm{~nm}(2.48 \mathrm{eV})$, Fig. 2(a), indicates the transformation of the pristine material into radical cations up to a potential of $1000 \mathrm{mV}$. Significant spectroscopic changes are observed after applying potentials higher than $1100 \mathrm{mV}$. While the maximum of the broad absorption band in the infrared range shifts and the transition at $835 \mathrm{~nm}(1.49 \mathrm{eV})$ gets clearly identifiable, the trend of the EPR signals changes, leading to a lower relative number of unpaired electrons. The decrease in EPR signal during oxidation of pentacene has been reported using another doping technique, namely chemical oxidation with iodine. ${ }^{18,28}$
For the number of free charge carriers for pentacene, values in the range of $4 \times 10^{20}-4 \times 10^{21} \mathrm{~cm}^{-3}$ are obtained upon chemical oxidation. ${ }^{18}$ The main advantage of the discussed method is that the oxidation level can be controlled by applying a certain potential. Thus, a correlation between oxidation potential and optical spectroscopy is possible. The loss in the EPR intensity reveals the disappearance of radical cations to a spinless species. The strong changes in vibrations in the range between $1700 \mathrm{~cm}^{-1}(0.21 \mathrm{eV})$ and $650 \mathrm{~cm}^{-1}(0.08 \mathrm{eV})$ after applying potentials higher than $1100 \mathrm{mV}$ as well as the isosbestic point at $700 \mathrm{~nm}(1.77 \mathrm{eV})$, Fig. 2(a), are an indication that the previous created radical cations are transformed into another species, which are described in the literature ${ }^{28}$ as dimers (pentacene) ${ }_{2}{ }^{2+}$. Still we cannot exclude the formation of dications at a high oxidation level from our spectroscopic data. In Fig. 4(c), the obtained spectroscopic changes are shown at the molecular level.

The situation for quinacridone is different compared to pentacene. Fig. 4(b) shows the results of in situ EPR measurements by applying certain potentials. Here, the EPR signal is depicted for a potential of $0 \mathrm{mV}$, during the first oxidation step around $1200 \mathrm{mV}$, and during the second oxidation step around $1650 \mathrm{mV}$. The slightly different potential values compared to previous 
measurements are explained in the same way as for pentacene. Again, no unpaired electrons are detected for the pristine quinacridone thin-film at $0 \mathrm{mV}$. At $1200 \mathrm{mV}$, an EPR signal appears which increases as oxidation proceeds. Thus, the measurement at $1650 \mathrm{mV}$, corresponding to the second oxidation step leads to an even higher relative number of unpaired electrons than we obtained during the first oxidation step. From a quantitative point of view, the relative number of spin $\frac{1}{2}$ at $1650 \mathrm{mV}$ is slightly more than double that of the potential at $1200 \mathrm{mV}$.

From EPR measurements, we confirm the formation of radical cations in quinacridone upon the first oxidation step. These charge carriers are characterized by an absorption band in the mid-IR range as well as by small changes in the UV-VIS range. As optical spectroscopy in the range between $1700 \mathrm{~cm}^{-1}$ $(0.21 \mathrm{eV})$ and $650 \mathrm{~cm}^{-1}(0.08 \mathrm{eV})$ suggests, the positive charge of the radical cation created upon oxidation is more localized on the nitrogen atom, because new peaks located at $1618 \mathrm{~cm}^{-1}$ and $1525 \mathrm{~cm}^{-1}$ appear, corresponding to $-\mathrm{C}=\mathrm{N}-$ stretching vibrations. A schematic sketch of the radical cation is depicted in Fig. 4(d). In addition, we mention the number of free charge carriers obtained upon chemical oxidation which can be related to the first oxidation peak in electrochemical oxidation reactions. Interestingly, mobility values in organic field-effect transistors of quinacridone are comparable to mobility values in pentacene, ${ }^{3}$ although the charge carrier concentration in quinacridone is smaller by a factor of $10^{4}-10^{5} \mathrm{~cm}^{-3} .^{18}$ The second oxidation step behaves differently for quinacridone, compared to its analogue pentacene. Several new absorption bands at $380 \mathrm{~nm}$ $(3.26 \mathrm{eV})$ and $870 \mathrm{~nm}(1.43 \mathrm{eV})$ arise in the UV-VIS range and the peak at $625 \mathrm{~nm}(1.98 \mathrm{eV})$ gets pronounced significantly. The two isosbestic points at $515 \mathrm{~nm}(2.41 \mathrm{eV})$ and $580 \mathrm{~nm}(2.14 \mathrm{eV})$ in Fig. 2(c) indicate that the radical cations are transformed into another oxidized species. Interestingly, the relative number of unpaired spins increases persistently. In addition, peaks located at $1618 \mathrm{~cm}^{-1}$ and $1525 \mathrm{~cm}^{-1}$ increase further, indicating the $-\mathrm{C}=\mathrm{N}-$ stretching vibration. This is an indication that the second oxidation occurs on the second nitrogen atom of quinacridone. Thus, the whole oxidation reaction ends up in the formation of a di(radical cation)ic species, a molecule which is two times positively charged and with two unpaired electrons. The positive charges of the di(radical cation)s are more localized on the nitrogen atoms. Compounds with heteroatoms as well as with a symmetric structure like quinacridone have shown similar results. ${ }^{29}$ In Fig. 4(d), we demonstrate how quinacridone looks like at the molecular level during the first and second oxidation steps.

\subsection{Reduction}

3.3.1 UV-VIS measurements. An analogous study is carried out for reduction reactions of pentacene and quinacridone. First, we consider spectral changes in the UV-VIS range. In Fig. 5(a), the absorption spectra of pentacene are shown with changing of the potential between $0 \mathrm{mV}$ and $-1700 \mathrm{mV}$. The black curve corresponds to the absorption spectrum of pristine pentacene, where the peaks have already been mentioned in the oxidation part, indicating the main absorption band pattern for this molecule. After reaching a potential of $-1400 \mathrm{mV}$, new absorption bands related to electronic transitions appear at $395 \mathrm{~nm}$ (3.14 eV), $430 \mathrm{~nm}(2.88 \mathrm{eV}), 780 \mathrm{~nm}(1.59 \mathrm{eV})$, and $870 \mathrm{~nm}(1.43 \mathrm{eV})$, getting more pronounced by applying more negative potentials. For the peak at $780 \mathrm{~nm}(1.59 \mathrm{eV})$ only a small increase in the baseline is observed for a potential of $-1400 \mathrm{mV}$ which results in an absorption band as reduction proceeds. The main absorption band pattern decreases during reduction reaction. In addition, this figure shows two isosbestic points around $487 \mathrm{~nm}(2.55 \mathrm{eV})$ and $698 \mathrm{~nm}(1.78 \mathrm{eV})$, indicating a transformation of the species into another reduced product. Interestingly, the reduction reaction starts around $-1140 \mathrm{mV}$ in cyclic voltammetric studies, Fig. 1(b), but absorption bands appear at potentials more negative than $-1400 \mathrm{mV}$. This observation will be discussed together with data recorded in the mid-IR range.

In situ spectroelectrochemical reduction for quinacridone is shown in Fig. 5(b) during the first reduction step and in Fig. 5(c) during the second reduction step. Data are plotted in absorbance by changing the potential between $0 \mathrm{mV}$ and $-2100 \mathrm{mV}$. First, we focus on the first reduction step, corresponding to the shoulder appearing in the cyclic voltammogram, see Fig. 1(c). In Fig. 5(b) spectra are obtained by changing the potential between $0 \mathrm{mV}$ and $-1700 \mathrm{mV}$. Again, the black curve indicates the absorption spectrum of this pristine hydrogenbonded semiconductor, which has been described previously. Its main absorption band pattern decreases slightly upon reduction. In addition, very small changes in absorption appear in the range between $600 \mathrm{~nm}(2.07 \mathrm{eV})$ and $670 \mathrm{~nm}(1.85 \mathrm{eV})$. This increase in absorbance is less pronounced compared to that one obtained at $625 \mathrm{~nm}(1.98 \mathrm{eV})$ during the first oxidation step, Fig. 2(b). Probably, the pristine material is only partially transformed into a reduced species. However, the shoulder in the cyclic voltammogram can be attributed to the first reduction step, as will be seen when discussing infrared data. Main changes in the UV-VIS range appear during the second reduction step by changing the potential between $-1800 \mathrm{mV}$ and $-2100 \mathrm{mV}$, see Fig. 5(c). The small optical changes occurring between $600 \mathrm{~nm}(2.07 \mathrm{eV})$ and $670 \mathrm{~nm}(1.85 \mathrm{eV})$ during the first reduction step result in an absorption band with its maximum around $633 \mathrm{~nm}(1.96 \mathrm{eV})$ by applying potentials more negative than $-1800 \mathrm{mV}$. In total, four new peaks located at $367 \mathrm{~nm}$ (3.38 eV), $633 \mathrm{~nm}(1.96 \mathrm{eV}), 770 \mathrm{~nm}(1.61 \mathrm{eV})$, and $840 \mathrm{~nm}$ $(1.48 \mathrm{eV})$ arise, while the main absorption band pattern decreases significantly. Furthermore, two isosbestic points at $445 \mathrm{~nm}$ $(2.79 \mathrm{eV})$ and $581 \mathrm{~nm}(2.13 \mathrm{eV})$ appear, showing a transformation of the product obtained during the first reduction step into another species. Since the second reduction step is much larger compared to the first one in the cyclic voltammogram, see Fig. 1(c), it might be that some part of the pristine material is directly transformed to the second reduced species.

3.3.2 IR measurements. Next, we consider spectral changes, e.g. electronic transitions as well as structural changes, resulting in changes in vibrational absorption bands, in the mid-IR range upon reduction. In Fig. 6(a), the difference spectra of pentacene are shown by changing the potential between $0 \mathrm{mV}$ and $-1700 \mathrm{mV}$ with the spectrum at $0 \mathrm{mV}$ taken as the reference spectrum. 


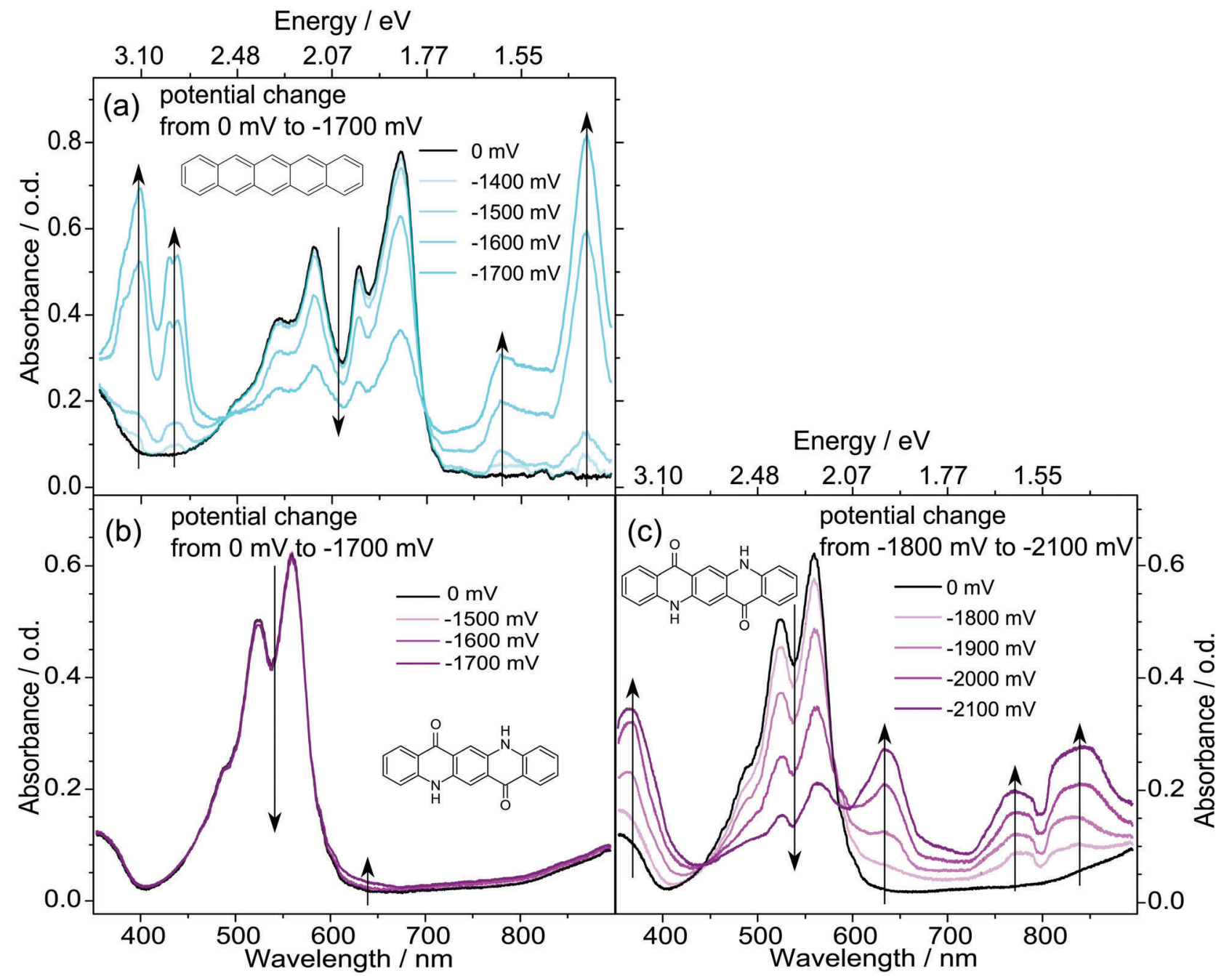

Fig. 5 Spectral changes in the UV-VIS range during electrochemical reduction of (a) pentacene by changing the potential between $0 \mathrm{mV}$ and $-1700 \mathrm{mV}$ and (b) quinacridone during the first reduction step by changing the potential between $0 \mathrm{mV}$ and $-1700 \mathrm{mV}$. (c) The second reduction step of quinacridone by changing the potential between $-1800 \mathrm{mV}$ and $-2100 \mathrm{mV}$. In all measurements, the spectrum obtained at $0 \mathrm{mV}$ shows the absorption spectrum of the considered pristine material. The direction of spectral changes is indicated with arrows in these figures.

As reduction starts, after applying a potential of $-1200 \mathrm{mV}$, a broad absorption band develops which increases by applying more negative potentials. Up to a potential of $-1300 \mathrm{mV}$ the broad absorption band shows an ill-defined maximum. After reaching a potential of $-1400 \mathrm{mV}$ the absorption band changes its shape, getting even more and more pronounced as reduction proceeds. The broad band shows its maximum at $4120 \mathrm{~cm}^{-1}$ $(0.51 \mathrm{eV})$. The negative vibrations, appearing in Fig. 6(a) will be discussed together with Fig. 6(b). The re-oxidation reaction of pentacene is shown in ESI, $\dagger$ Fig. S3, indicating an irreversible process, because the spectral response of the pristine material is not obtained. In Fig. 6(b), the range between $1700 \mathrm{~cm}^{-1}$ $(0.21 \mathrm{eV})$ and $650 \mathrm{~cm}^{-1}(0.08 \mathrm{eV})$ is shown. The spectrum at $0 \mathrm{mV}$ is taken again as a reference spectrum. By applying potentials up to $-1300 \mathrm{mV}$ no significant new vibrations appear, just the baseline of these spectra shifts. After applying a potential of $-1400 \mathrm{mV}$, positive peaks arise in the range between $1260 \mathrm{~cm}^{-1}$ and $1650 \mathrm{~cm}^{-1}$, indicating changes in $-\mathrm{C}=\mathrm{C}-$ and $-\mathrm{C}-\mathrm{H}$ vibrations. The negative peaks in Fig. 6(a) and (b) which get more and more pronounced due to more negative potentials represent vibrations from pristine pentacene as well as the interplay with PVA. The explanation for the negative appearance of vibrations is the same as it has been mentioned for oxidation.

Finally, we summarize all spectroscopic data obtained for pentacene in the reduction case. The explanation of the reduction reaction can be carried out in an analogous manner as it has been done for the oxidation reaction. Although pentacene shows only one reduction step in the cyclic voltammogram, Fig. 1(a), we can distinguish between low and high reduction levels from a spectroscopic point of view. In the low reduction case, up to potentials of $-1300 \mathrm{mV}$, no changes appear in the UV-VIS range. One broad absorption band with an ill-defined maximum arises for pentacene in the infrared range. In this potential range, the changes in vibrations in the range between $1700 \mathrm{~cm}^{-1}(0.21 \mathrm{eV})$ and $650 \mathrm{~cm}^{-1}(0.08 \mathrm{eV})$ are insufficient to describe them in more detail. Since the 


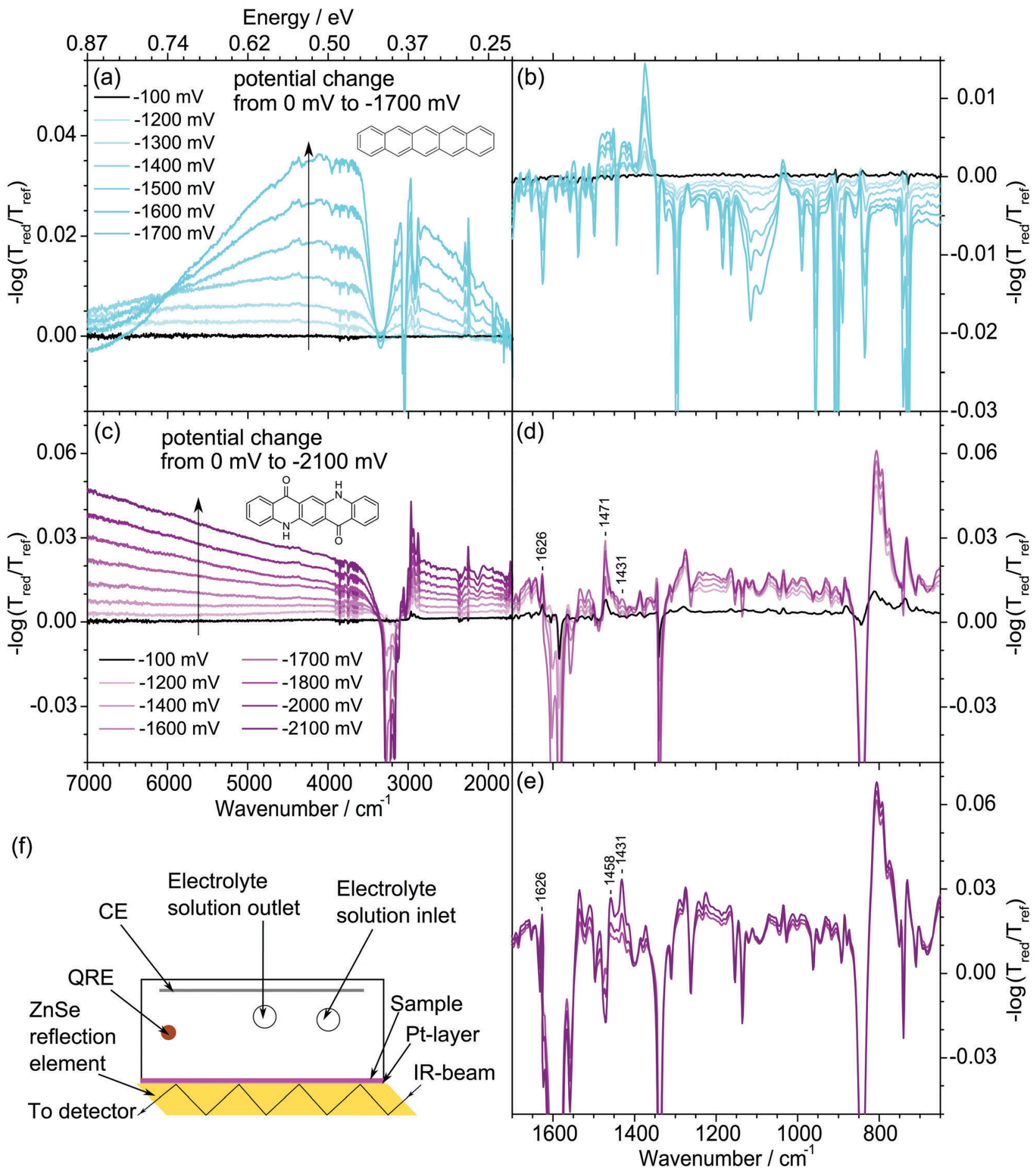

Fig. 6 (a) Spectral changes in the mid-IR range during electrochemical reduction of pentacene by changing the potential from $0 \mathrm{mV}$ to $-1700 \mathrm{mV}$, with the spectrum at $0 \mathrm{mV}$ taken as the reference spectrum. (b) The corresponding spectral range between $1700 \mathrm{~cm}^{-1}(0.21 \mathrm{eV}) \mathrm{and} 650 \mathrm{~cm}^{-1}(0.08 \mathrm{eV})$. (c) The first and second reduction steps of quinacridone by changing the potential between $0 \mathrm{mV}$ and $-2100 \mathrm{mV}$. The reference spectrum is taken at $0 \mathrm{mV}$. (d) and (e) The corresponding spectral ranges between $1700 \mathrm{~cm}^{-1}(0.21 \mathrm{eV})$ and $650 \mathrm{~cm}^{-1}(0.08 \mathrm{eV})$ for the first reduction and the second reduction, respectively. The arrows in the graphs indicate the direction of spectral changes. (f) The experimental setup for in situ mid-IR spectroelectrochemistry.

spectroscopic results are similar to those obtained for the oxidation reaction, we presume the formation of radical anions at a low reduction level, up to a potential of $-1300 \mathrm{mV}$. After applying potentials more negative than $-1400 \mathrm{mV}$, at a high reduction level, four peaks appear at $395 \mathrm{~nm}(3.14 \mathrm{eV}), 430 \mathrm{~nm}$ $(2.88 \mathrm{eV}), 780 \mathrm{~nm}(1.59 \mathrm{eV})$, and $870 \mathrm{~nm}(1.43 \mathrm{eV})$ in the UV-VIS range, getting more pronounced as reduction proceeds. The main absorption band pattern decreases upon these applied 
potentials. The broad absorption band in the mid-IR range changes its shape and shows its maximum at $4120 \mathrm{~cm}^{-1}$ $(0.51 \mathrm{eV})$. In addition, the difference spectra in the range between $1700 \mathrm{~cm}^{-1}(0.21 \mathrm{eV})$ and $650 \mathrm{~cm}^{-1}(0.08 \mathrm{eV})$ change significantly. The positive arising peaks are attributed to new $-\mathrm{C}=\mathrm{C}-$ and $-\mathrm{C}-\mathrm{H}$ vibrations, indicating the formation of a new species. The transformation of the already reduced product (assumed radical anions) into another product is also supposed by the isosbestic points, appearing in Fig. 5(a). In analogy to the oxidation reaction, we adopt the same model for pentacene in the reduction case. The created radical anions at a low reduction level are transformed to a spinless species at a high reduction level which is either a dianion or a dimer (pentacene) $)_{2}^{2-}$. In Fig. 7(a), a supposed schematic sketch of the reduction of pentacene at the molecular level is demonstrated.

For quinacridone analogous in situ spectroelectrochemical measurements have been carried out. The corresponding difference spectra in the range between $7000 \mathrm{~cm}^{-1}(0.87 \mathrm{eV})$ and $1700 \mathrm{~cm}^{-1}(0.21 \mathrm{eV})$ are shown in Fig. 6(c) by changing the potential between $0 \mathrm{mV}$ and $-2100 \mathrm{mV}$ with the spectrum at $0 \mathrm{mV}$ taken as the reference spectrum. A broad absorption band develops, starting after applying a potential of $-1200 \mathrm{mV}$, and has its maximum beyond the possible measuring range. This increase in absorption occurs already at $-1200 \mathrm{mV}$, indicating that the shoulder described in the cyclic voltammogram, Fig. 1(c), is attributed to the first reduction step. Since the absorption bands of the first and second reduction steps grow together, we plot them in one graph. Again, the negative peaks in this graph will be mentioned together with Fig. 6(d) and (e). The reversibility of both reduction peaks of quinacridone is shown in ESI, $\dagger$ Fig. S4. The range between $1700 \mathrm{~cm}^{-1}(0.21 \mathrm{eV})$ and $650 \mathrm{~cm}^{-1}(0.08 \mathrm{eV})$ is plotted in Fig. 6(d) for the first reduction step and in Fig. 6(e) for the second reduction step. During the first reduction step, Fig. 6(d), several positive peaks appear by changing the potential between $0 \mathrm{mV}$ and $-1700 \mathrm{mV}$. Since the maximum of the first reduction step is at $-1620 \mathrm{mV}$ in the cyclic voltammetric studies, the potential at $-1700 \mathrm{mV}$ already shows a different spectral behavior which can be attributed to the second reduction step. Thus, the spectrum obtained at $-1700 \mathrm{mV}$ will be discussed together with Fig. 6(e). The vibration located at $1626 \mathrm{~cm}^{-1}$ indicates $-\mathrm{C}-\mathrm{O}^{-}$vibrations. Positive peaks at $1471 \mathrm{~cm}^{-1}$ and $1431 \mathrm{~cm}^{-1}$ are assigned to $-\mathrm{C}=\mathrm{C}-$ vibrations. All other positive peaks originate from $-\mathrm{C}=\mathrm{C}-,-\mathrm{C}-\mathrm{C}-$, and $-\mathrm{C}-\mathrm{H}$ vibrations.

Spectral changes in the low energy range are plotted in Fig. 6(e) for the second reduction step. For these measurements, we change the potential between $-1800 \mathrm{mV}$ and $-2100 \mathrm{mV}$ (vibrational changes obtained at $-1700 \mathrm{mV}$ will be discussed here, too). The $-\mathrm{C}-\mathrm{O}^{-}$peak at $1626 \mathrm{~cm}^{-1}$ increases further. In addition, some $-\mathrm{C}=\mathrm{C}-$ and $-\mathrm{C}-\mathrm{C}$ - vibrations, which appeared upon the first reduction step, decrease upon the second reduction step and new ones arise. Thus, the vibration located at $1471 \mathrm{~cm}^{-1}$ decreases. The signals at $1458 \mathrm{~cm}^{-1}$ and $1431 \mathrm{~cm}^{-1}$ are attributed to new $-\mathrm{C}=\mathrm{C}$ - vibrations. The mentioned spectral changes might be an indication for better aromatic stabilization. All other positive peaks are assigned to $-\mathrm{C}=\mathrm{C}-,-\mathrm{C}-\mathrm{C}-$, and $-\mathrm{C}-\mathrm{H}$ vibrations. The appearance of negative peaks in the broad absorption band, Fig. 6(c), as well as in the low energy range, Fig. 6(d) and (e), show loss of vibration of the pristine thin-film and are described analogously as for the oxidation reaction.

Next, we summarize all spectroscopic changes in quinacridone upon reduction by in situ spectroelectrochemical measurements. For quinacridone, the situation is different from that of pentacene. Initially, we focus on the first reduction step, appearing as a small shoulder in the cyclic voltammogram, Fig. 1(c), by applying potentials up to $-1700 \mathrm{mV}$. In the UV-VIS range, only slight changes in the range between $600 \mathrm{~nm}(2.07 \mathrm{eV})$ and $670 \mathrm{~nm}(1.85 \mathrm{eV})$ as well as in the main absorption band pattern are discernible. As reduction

(a)

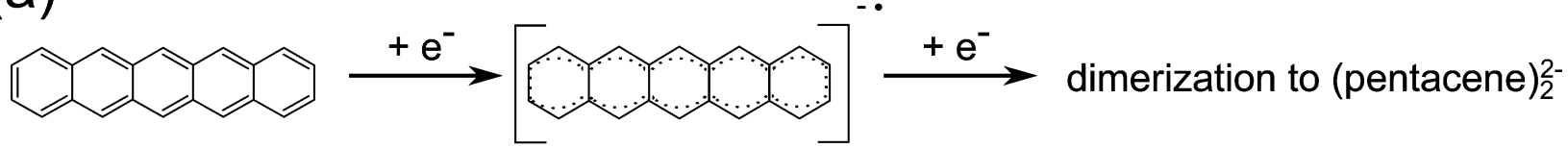<smiles></smiles><smiles></smiles>
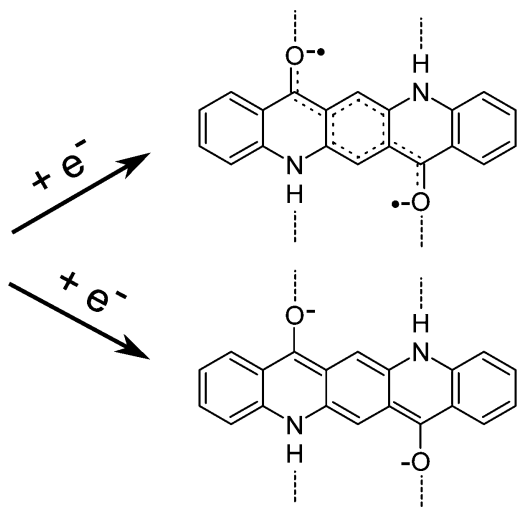

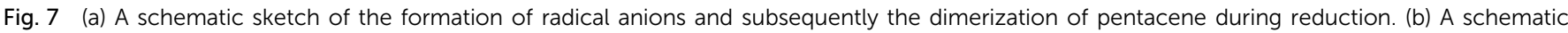

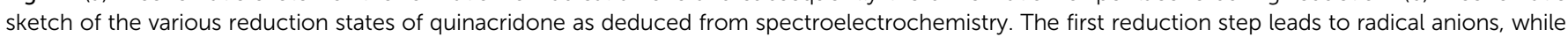
the second reduction process gives either di(radical anion)s or dianions with negative charges localized on the oxygen atoms. 
starts by applying a potential of $-1200 \mathrm{mV}$ a new broad absorption band arises in the mid-IR range with its maximum beyond the measuring range. In the range between $1700 \mathrm{~cm}^{-1}(0.21 \mathrm{eV})$ and $650 \mathrm{~cm}^{-1}(0.08 \mathrm{eV})$, significant changes in $-\mathrm{C}-\mathrm{O}^{-}$as well as in $-\mathrm{C}=\mathrm{C}-$ vibrations occur. These data suggest, a localization of charged species on one of the two oxygen atoms in the heteroatomic ring system, leading to the formation of a semiquinoid structure as has already been mentioned for oxidation. We assume that radical anions are generated in quinacridone during the first reduction step, because analogous optical spectroscopic changes as in the first oxidation step are obtained. Changes in vibrational absorption bands in the low energy range, Fig. 6(d), show a different spectral behavior to those depicted in Fig. 6(e), which is a further indication that the shoulder in the cyclic voltammogram can be attributed to a separate reduction step. After applying a potential more negative than $-1700 \mathrm{mV}$, during the second reduction step, several absorption bands related to transitions arise. The band at $633 \mathrm{~nm}(1.96 \mathrm{eV})$, where only small changes have been observed during the first reduction step, increases to a significant peak. In addition, three further peaks arise simultaneously at $367 \mathrm{~nm}(3.38 \mathrm{eV}), 770 \mathrm{~nm}(1.61 \mathrm{eV})$, and $840 \mathrm{~nm}$ $(1.48 \mathrm{eV})$, while the main absorption band pattern decreases. In the infrared range, the same broad absorption band as mentioned previously increases, showing no significant differences between the first and the second reduction steps. Interestingly, the $-\mathrm{C}-\mathrm{O}^{-}$ vibration changes in the same way as described upon the first reduction step. In addition, $-\mathrm{C}=\mathrm{C}-$ and $-\mathrm{C}-\mathrm{C}-$ vibrations change compared to the first reduction step. From optical spectroscopy, we suggest that the second reduction step occurs on the second oxygen atom in quinacridone. As in the case of oxidation, we attribute these spectroscopic changes to the formation of di(radical anion)s where the negative charges are more localized on the oxygen atoms. However, other reduced products such as quinoid-like structures resulting in dianions cannot be excluded. The isosbestic points at $445 \mathrm{~nm}(2.79 \mathrm{eV})$ and $581 \mathrm{~nm}(2.13 \mathrm{eV})$ in Fig. 5(c) support the idea that radical anions are transformed into another product upon the second reduction reaction. In Fig. 7(b), we show the reduction reaction of quinacridone through the oxygen atom at the molecular level. It is conceivable that even the pristine material is transformed into di(radical anion)s or dianions because the second reduction peak is significantly larger.

\section{Conclusions}

We report on the formation of different charge carriers in pentacene as well as in quinacridone upon redox reactions. Optical measurements ranging from UV-VIS to mid-IR allow the tracking of electronic as well as vibrational changes occurring during oxidation and reduction reactions, respectively. Although pentacene shows only one oxidation peak in the cyclic voltammetric studies, we distinguish between low and high oxidation levels due to the optical spectroscopy results including EPR measurements. We found that the radical cations created at a low oxidation level dimerize as oxidation proceeds. In contrast to pentacene, quinacridone shows two well-defined oxidation peaks in the cyclic voltammogram. During the first oxidation step, a broad absorption band arises above all in the mid-IR range. In addition, unpaired electrons are detected, resulting in the formation of radical cations. Additional spectral changes appear during the second oxidation step, but the relative number of unpaired spins further increases, leading to the formation of di(radical cation)s. From vibrational changes in the mid-IR range we suggest that the radical cations are more localized on the nitrogen atom in the heteroatomic ring system of quinacridone than for pentacene. In analogy to this, the reduction reaction is described for both pigments.

\section{Acknowledgements}

Financial support by the Austrian Science Foundation (FWF) within the Wittgenstein Prize scheme for Prof. Sariciftci (FWF [Z 222-N19] Solare Energieumwandlung) and Indigo Circuits (FWF [TRP 294-N19]) is gratefully acknowledged. S. Pluczyk was a scholar supported by the "Doktoris-scholarship program for an innovative Silesia", co-financed by the European Union within the European Social Fund.

\section{References}

1 E. D. Glowacki, G. Voss and N. S. Sariciftci, Adv. Mater., 2013, 25, 6783-6800.

2 E. D. Glowacki, M. Irimia-Vladu, M. Kaltenbrunner, J. Gasiorowski, M. S. White, U. Monkowius, G. Romanazzi, G. P. Suranna, P. Mastrorilli, T. Sekitani, S. Bauer, T. Someya, L. Torsi and N. S. Sariciftci, Adv. Mater., 2013, 25, 1563-1569.

3 E. D. Glowacki, L. Leonat, M. Irimia-Vladu, R. Schwodiauer, M. Ullah, H. Sitter, S. Bauer and N. S. Sariciftci, Appl. Phys. Lett., 2012, 101, 023305.

4 D. Berg, C. Nielinger, W. Mader and M. Sokolowski, Synth. Met., 2009, 159, 2599-2602.

5 C. Li and H. Wonneberger, Adv. Mater., 2012, 24, 613-636. 6 H. Yanagisawa, J. Mizuguchi, S. Aramaki and Y. Sakai, Jpn. J. Appl. Phys., 2008, 47, 4728-4731.

7 W. Herbst and K. Hunger, Industrial Organic Pigments: Production, Properties, Applications, Wiley-VCH, Weinheim, 3rd edn, 2004.

8 H. Zollinger, Color Chemistry. Syntheses, Properties and Applications of Organic Dyes and Pigments, Wiley-VCH, Weinheim, 3rd edn, 2003.

9 K. Hunger, Rev. Prog. Color. Relat. Top., 2005, 35, 76-89.

10 E. D. Glowacki, G. Romanazzi, C. Yumusak, H. Coskun, U. Monkowius, G. Voss, M. Burian, R. T. Lechner, N. Demitri, G. J. Redhammer, N. Sünger, G. P. Suranna and S. Sariciftci, Adv. Funct. Mater., 2015, 25, 776-787.

11 E. D. Glowacki, R. R. Tangorra, H. Coskun, D. Farka, A. Operamolla, Y. Kanbur, F. Milano, L. Giotta, G. M. Farinola and N. S. Sariciftci, J. Mater. Chem. C, 2015, 3, 6554-6564. 
12 M. Jakesova, D. H. Apaydin, M. Sytnyk, K. Oppelt, W. Heiss, N. S. Sariciftci and E. D. Glowacki, Adv. Funct. Mater., 2016, 26, 5248-5254.

13 A. Bard and L. Faulkner, Electrochemical Methods: Fundamentals and Applications, Wiley, New York, 2001.

14 S. P. Best, S. J. Borg and K. A. Vincent, Spectroelectrochemistry, The Royal Society of Chemistry, 2008, pp. 1-30.

15 L. Dunsch, J. Solid State Electrochem., 2011, 15, 1631-1646.

16 W. R. Heineman, J. Chem. Educ., 1983, 60, 305-308.

17 C. Kvarnstrom, H. Neugebauer and A. Ivaska, in Advanced Functional Molecules and Polymers, ed. H. S. Nalwa, Godon and Breach Science, Oxford, 2001, ch. 6, vol. 2, pp. 139-170.

18 C. Enengl, S. Enengl, M. Havlicek, P. Stadler, E. D. Glowacki, M. C. Scharber, M. White, K. Hingerl, E. Ehrenfreund, H. Neugebauer and N. S. Sariciftci, Adv. Funct. Mater., 2015, 25, 6679-6688.

19 S. Enengl, C. Enengl, P. Stadler, H. Neugebauer and N. S. Sariciftci, ChemPhysChem, 2015, 16, 2206-2210.

20 A. W. Hassel, K. Fushimi and M. Seo, Electrochem. Commun., 1999, 1, 180-183.

21 H. Neugebauer, A. Neckel, G. Nauer, N. Brinda-Konopik, F. Garnier and G. Tourillon, J. Phys., 1983, 44, 517-520.
22 H. Neugebauer and N. S. Sariciftci, in Lower-Dimensional Systems and Molecular Electronics, ed. R. M. Metzger, P. Day and G. C. Papavassiliou, Springer, US, 1990, vol. 248, pp. 401-406.

23 H. Neugebauer, Macromol. Symp., 1995, 94, 61-73.

24 Q. Miao, T.-Q. Nguyen, T. Someya, G. B. Blanchet and C. Nuckolls, J. Am. Chem. Soc., 2003, 125, 10284-10287.

25 W. Siebrand and M. Z. Zgierski, in Organic Molecular Aggregates: Electronic Excitation and Interaction Processes, ed. P. Reineker, H. Haken and H. C. Wolf, Springer, Berlin Heidelberg, 1983, ch. 5, vol. 49, pp. 136-144.

26 K. Ye, J. Wang, H. Sun, Y. Liu, Z. Mu, F. Li, S. Jiang, J. Zhang, H. Zhang, Y. Wang and C.-M. Che, J. Phys. Chem. B, 2005, 109, 8008-8016.

27 S. Stafström, J. L. Brédas, A. J. Epstein, H. S. Woo, D. B. Tanner, W. S. Huang and A. G. MacDiarmid, Phys. Rev. Lett., 1987, 59, 1464-1467.

28 M. Brinkmann, V. Videva, A. Bieber, J. Andr, P. Turek, L. Zuppiroli, P. Bugnon, M. Schaer, F. Nuesch and R. Humphry-Baker, J. Phys. Chem. A, 2004, 108, 8170-8179. 29 J. Hankache and O. S. Wenger, Chem. Rev., 2011, 111, 5138-5178. 